Revista Mídia e Cotidiano

Artigo Seção Temática

Volume 12, Número 1, abril de 2018

Submetido em: 28/02/2018

Aprovado em: 28/04/2018

\title{
A DEMOCRATIZAÇÃO DA MÍDIA NO BRASIL PÓS-CONFECOM (2010-2017): proposta de um estudo de caso
}

\section{THE DEMOCRATIZATION OF MEDIA IN POST-CONFECOM BRAZIL (2010-2017): a case study proposal}

\author{
Carlos Henrique DEMARCHI ${ }^{1}$; Maria Teresa Miceli KERBAUY ${ }^{2}$
}

\section{Resumo:}

O presente artigo tem como objetivo analisar, a partir das ações da sociedade civil organizada, o debate público sobre a democratização da mídia no Brasil no período 2010-2017, após a $1^{\text {a }}$ Confecom (Conferência Nacional de Comunicação). A base do estudo é revisão bibliográfica, análise documental e entrevistas com representantes do movimento pela democratização dos meios. Conclui-se que a principal pauta do movimento social após a conferência - o marco regulatório da mídia - retrocedeu no período histórico analisado, havendo dificuldades para a regulação do setor de radiodifusão.

Palavras-chave: Democratização; Regulação; Políticas públicas; Movimentos sociais; Grande mídia.

\begin{abstract}
:
Focusing on the actions of organized civil society, this paper aims to analyse media democratization in Brazil in the 2010-2017 period, after Confecom (1st Brazilian Conference for Communications). The study is based on bibliographical research, document analysis and interviews with representatives of the movement for media democratization. We reach the conclusion that the prioritary demand of the social movements after Confecom - a new media regulation in the sector - has receded in the period we have analyzed, and many difficulties for the regulation of broadcasting were found.
\end{abstract}

Keywords: Democratization; Regulation; Public policies; Social movements; Mainstream media.

\footnotetext{
${ }^{1}$ Doutorando em Comunicação pela Universidade Estadual Paulista (Unesp). Docente no curso de Comunicação Social do Centro Universitário Católico Salesiano Auxilium de Araçatuba (SP). Membro do grupo de pesquisa Estado e governo. E-mail: carlosdemarchi@faac.unesp.br.

${ }^{2}$ Doutora em Ciências Sociais pela PUC/SP. Pós-doutorado pelo Instituto de Iberoamerica/Universidade de Salamanca/ Espanha. Docente do Programa de Pós-graduação em Ciências Sociais e de Comunicação da UNESP. Bolsista Produtividade do CNPq. E-mail: teresa.kerbauy@gmail.com.
} 


\section{míDiA

\section{INTRODUÇÃO}

O panorama brasileiro na área das comunicações é marcado pela concentração da propriedade dos meios. É o que também confirmou recente pesquisa elaborada pelo Intervozes em parceria com a Repórteres Sem Fronteiras sobre os controladores da mídia no país (MEDIA, 2017).

O levantamento mostrou que, entre 50 veículos investigados, 26 pertencem a grupos econômicos de comunicação. Desse total, os quatro principais grupos de mídia têm audiência nacional que ultrapassa $70 \%$ no caso da televisão aberta, meio de comunicação mais consumido no país.

Sem uma política pública clara para a área de radiodifusão comercial, há no Brasil um cenário de disputa pela hegemonia do setor, sendo a sociedade civil organizada um dos atores sociais a se contraporem ao sistema de mídia existente, reivindicando mudanças diante da concentração dos meios.

Nas últimas décadas, em que as políticas da área favoreceram o empresariado, os setores organizados da sociedade expandiram as ações para cobrar do governo medidas contestando o poder da grande mídia e seus efeitos.

Em 2009, a realização da primeira conferência setorial para a área em Brasília - a Confecom (Conferência Nacional de Comunicação), cujo tema foi "Comunicação: meios para a construção de direitos e de cidadania na era digital" - aumentou as expectativas de alterações no quadro de concentração existente na área. Contudo, no cenário atual pósConfecom, ocorreram retrocessos nas políticas públicas do setor, demonstrados pela redução de canais de participação social da sociedade civil e por medidas de desmonte no campo da comunicação pública.

Frente a essa realidade, o presente artigo analisa as discussões contemporâneas sobre a luta pela democratização de comunicação no Brasil. O trabalho está estruturado em três partes. Na primeira delas, busca-se localizar teoricamente a questão das lutas recentes pela regulação da mídia. Na sequência, o trabalho enfatiza a atuação da sociedade civil nesse processo após a Confecom (2010-2017). Por fim, são apontados os resultados parciais da pesquisa. 


\title{
MEIOS DE COMUNICAÇÃO, PODER E REGULAÇÃO
}

Nas democracias contemporâneas, a radiodifusão é definida como a prestação do serviço público de rádio e televisão. Essa atividade, via de regra, é regulada pelo poder público, mediante o acompanhamento periódico do serviço prestado e atualização dos marcos legais.

Ante o processo de convergência tecnológica, esperava-se dos governos a revisão das leis que disciplinam o setor. Porém, o aprofundamento da lógica neoliberal veio por intensificar o domínio do mercado sobre as atividades socioculturais, além de reduzir as políticas públicas favoráveis à participação social na área.

Em países latino-americanos, Sorj (2011) concorda com a complexidade na elaboração de novas legislações para o setor. "Não é demais lembrar que qualquer legislação deverá orientar-se em primeiro lugar pelo objetivo de garantir a liberdade de expressão dos cidadãos frente ao poder do Estado e ao poder econômico" (p. 22).

O alto nível de concentração de propriedade é outro problema frequentemente enfrentado em países da região, dado que muitas vezes um mesmo grupo de comunicação é proprietário de rádio, jornal impresso e televisão, gerando a propriedade cruzada. Sob este prisma:

\begin{abstract}
Se a concentração da propriedade é prejudicial em qualquer área da atividade econômica, pelos abusos de poder que acarreta, no caso da mídia, tal concentração adquire uma nocividade adicional, pelo caráter específico do bem público que ela produz e dissemina. Paradoxalmente, esta mesma concentração exacerba o embate entre meios de comunicação e governos, pois a concentração de poder de certos grupos empresariais os transforma em alvos fáceis de atacar por governos que se sentem prejudicados por estes grupos. Em suma, a concentração extrema pode fragilizar o próprio sistema privado de comunicação. A extrema concentração não deve ser confundida com a existência de grupos de mídia economicamente sólidos, pois isto lhes oferece maior independência frente aos poderes de estado e governo em exercício. Tanto na formulação legal como em sua aplicação, o combate à concentração da propriedade deve ser orientado por regras claras e universais, por agências reguladoras autônomas do poder governamental. (SORJ, 2011, p. 25-26)
\end{abstract}

No Brasil, além da necessidade histórica de atualizar a legislação para a radiodifusão ${ }^{3}$, não há uma política pública nítida para o campo das comunicações. $\mathrm{O}$ governo, o empresariado da radiodifusão e a sociedade civil organizada são os principais atores sociais na disputa por interesses nas políticas que disciplinam as comunicações.

\footnotetext{
${ }^{3}$ O principal marco regulatório é o Código Brasileiro de Telecomunicações (1962). A Constituição Federal de 1988, por meio de cinco artigos, fixou as diretrizes para as comunicações, porém falta a regulamentação de artigos desta lei.
} 
Porém, conforme Lima (2011), essa disputa acaba prevalecendo entre os dois primeiros atores, sendo a sociedade civil um grupo que busca interferir nas políticas da área, por meio de ações e mobilizações, cujos resultados práticos foram pontuais.

Sorj (2011, p. 8) considera que "para avançar este debate, é fundamental que ele não seja dominado, como ocorre atualmente, pela polarização entre empresários e governos, que inviabiliza um diálogo cujo objetivo seja o bem público". Isto posto, entende-se que os interesses de cidadania devem predominar sobre os interesses em jogo entre os atores sociais envolvidos.

Neste sentido, a regulação da mídia é tomada como saída para a resolução de problemas como a concentração e a ausência de participação social nas políticas que caracterizam a realidade brasileira. Essa discussão remete ao conceito de políticas públicas, pois "refere-se ao processo de criação de opções sobre o que fazer a respeito de um problema público" (HOWLETT; HAMESH; PERL, 2013, p. 123).

Em outras palavras:

A formulação da política, portanto, envolve a identificação e a determinação das possíveis soluções para os problemas políticos ou, para dizê-lo de outra maneira, a exploração das várias opções ou cursos alternativos de ação disponíveis para enfrentá-los. (Ibid., p. 123)

A análise do caso brasileiro revela a complexidade da luta do segmento da sociedade civil em promover mudanças na área. Isso porque as políticas públicas envolvem atores cercados por restrições que tentam compatibilizar objetivos políticos com meios políticos em busca de soluções para os problemas (Ibid.).

Estudos da Unesco ${ }^{4}$ indicam que "um sólido marco regulatório envolve tanto o estabelecimento, por lei, de políticas públicas com fortes objetivos e regras quanto a criação de uma autoridade reguladora independente que zelará pelo cumprimento da legislação" (MENDEL; SALOMON, 2011, p. 12).

Outro aspecto destacado em publicação da Unesco faz menção à participação da sociedade civil no processo de regulação da mídia, pois:

A sociedade civil pode exercer uma grande influência positiva para sustentar a independência do órgão regulador, inclusive por meio da pressão pública sobre as instâncias de interferência política. Nos países onde a sociedade civil tem formas mais maduras de organização, geralmente há mais consultas públicas. O exemplo alemão é particularmente interessante, devido à sua ênfase na

\footnotetext{
${ }^{4}$ Organização das Nações Unidas para a Educação, a Ciência e a Cultura.
} 
representação comunitária. Ao invés de focar na imparcialidade, o modelo alemão busca equilibrar os diferentes interesses da comunidade permitindo que diversos grupos (como a Igreja Católica, os sindicatos etc.) indiquem representantes para trabalhar nos órgãos de monitoramento das autoridades reguladoras regionais. (Ibid., p. 13)

$\mathrm{Na}$ luta por maior protagonismo nas políticas adotadas, em que a grande mídia detém poder e centralidade na veiculação de conteúdos, a sociedade civil deve se manter articulada para cobrar transparência no uso das concessões públicas de radiodifusão.

A literatura ainda traz a possibilidade de haver a autorregulação da mídia que, segundo Puddephatt (2011), consiste na combinação de padrões e códigos de práticas necessários para apoiar a liberdade de expressão e balizar o monitoramento e a responsabilização dos veículos de comunicação. Neste sentido:

\begin{abstract}
Os benefícios da autorregulação são bem conhecidos: ela preserva a independência da mídia e a protege contra a interferência política de governos. Pode ser mais eficiente do que um sistema de regulação governamental, já que a mídia entende seu ambiente melhor do que o governo - mesmo que as empresas do setor utilizem este conhecimento muito mais para atender a seus próprios interesses comerciais do que ao interesse público. Quando o ambiente se torna global (com a internet e outras plataformas digitais) e as questões de jurisdição ficam mais complexas, a autorregulação também se mostra mais apropriada em vários sentidos. O governo gasta menos, porque é a própria indústria que assume os custos de adaptação, seguindo regras muito mais flexíveis do que as estabelecidas na regulação estatal. (PUDDEPHATT, 2011, p.12-13)
\end{abstract}

Mesmo que a autorregulação seja um mecanismo aceito pelo setor empresarial de mídia, há que se reconhecer que, em certos contextos, não seria a opção adequada, pois a mídia poderia reforçar o poder de interesses dominantes e agravar desigualdades sociais pela exclusão de vozes críticas ou marginalizadas (Ibid.).

O exemplo brasileiro denota a necessidade de haver um sistema de mídia com maior pluralidade de ideias e diversidade de conteúdos, aspectos que poderiam ser solucionados por meio de políticas do governo. Cabe ressaltar, ainda, a relevância de maior equilíbrio entre os sistemas comercial, estatal e público, garantias previstas na Constituição Federal de 1988, mas até hoje não implementadas.

\title{
A AGENDA DA DEMOCRATIZAÇÃO DA MÍDIA NO PÓS-CONFECOM (2010-2017)
}

A pesquisa integra um estudo de caso que visa compreender como se deu o debate público sobre a democratização da comunicação após a $1^{\text {a }}$ Conferência Nacional de 
Comunicação (Confecom), realizada em Brasília, capital federal, em 2009. Para Yin (2010), o estudo de caso é uma investigação empírica de um fenômeno contemporâneo em profundidade e em seu contexto de vida real, especialmente quando esse entendimento engloba relevantes condições contextuais.

A conferência setorial em si é evocada como um momento progressista na luta pela democratização da mídia, em virtude de ter sido um fórum inédito de mobilização na sociedade brasileira para discutir as comunicações (DANTAS, 2013). Entretanto, existe a compreensão de que se perdeu uma oportunidade no pós-Confecom:

\begin{abstract}
Seus resultados, sobretudo, e principalmente, a abertura de canal de diálogo entre os distintos campos da sociedade civil (no sentido gramsciano), teria possibilitado pactuar um projeto político de largo alcance, sustentado num adequado marco regulatório que incorporasse as demandas por pluralidade e diversidade no mercado de ideias, pacto a ser costurado por um governo com poder de barganha a ele dado pela demanda empresarial por recursos financeiros públicos, seja como financiamento ou participação acionária, seja como verbas publicitárias. Certamente, como todo pacto social, não seria uma negociação fácil. As partes, inclusive os ativistas da democratização, sabem defender com denodo suas demandas. Já o campo mediático, por seu lado, conta, como bem sabemos, com todos os recursos do agendamento. Mas um governo dotado de vontade, sobretudo e principalmente quando não há um ambiente inicial de consenso, inclusive no interior do capital, pode coordenar o debate, esclarecer propostas, fazer aos poucos prevalecer a razão onde predominam as paixões dos discursos panfletários de todos os lados, até porque ao governo deve caber pensar, não conforme os interesses das partes, mas na síntese do todo. (DANTAS, 2013, p. 227)
\end{abstract}

Infere-se que, inicialmente, havia um quadro propício ao debate, com espaços de diálogo dentro do Governo Federal, realidade que se estendeu até o final de 2015. Naquele período, a principal pauta dos grupos em defesa da democratização dos meios de comunicação era o estabelecimento de um novo marco regulatório para a mídia, ou seja, a atualização regulatória das leis do campo da radiodifusão. Havia um maior conjunto de atividades do movimento social em torno de demandas pela atualização legal.

Não obstante, no quadro pós-Confecom (2010-2017), compreende-se que a agenda do marco regulatório não avançou, havendo dificuldades para um efetivo debate público entre os principais atores sociais envolvidos nas políticas de comunicação sociedade civil, governo e empresariado (informação verbal) ${ }^{5}$. No período analisado como um todo, verificou-se que a discussão pública em torno da democratização da mídia

\footnotetext{
${ }^{5}$ Informação verbal obtida na conferência "Meios de comunicação, regulação e democracia", que encerrou o $3^{\circ}$ Encontro Nacional pelo Direito à Comunicação (ENDC) na Universidade de Brasília, em 28 de maio de 2017.
} 


\section{míDiA

ficou restrita a ações da sociedade civil, que prosseguiu com o debate, principalmente na internet, redes sociais e encontros dos movimentos sociais, mas teve os canais de diálogo reduzidos junto ao Governo Federal, se comparado ao período de realização da conferência.

Em geral, as conferências nacionais resultam em planos nacionais para as áreas nas quais ocorrem, revertendo em políticas públicas. No caso da Confecom, as 633 resoluções aprovadas no evento há oito anos não foram implementadas, entre elas a garantia de fiscalização, com controle social e participação popular, nos processos de financiamento e acompanhamento das obrigações fiscais e trabalhistas das emissoras, a criação de políticas para não criminalizar as rádios comunitárias, o estímulo à produção de conteúdo nacional e independente e a imposição de limites na afiliação entre emissoras.

Segundo a secretária geral do $\mathrm{FNDC}^{6}$, Bia Barbosa, a falta de vontade política dos governos foi o principal fator que impediu avanços na pauta do marco regulatório e, por assim dizer, de ações que levassem à efetivação de políticas públicas para o setor. "Faltou vontade política do governo federal de pegar essas resoluções e se apropriar delas, transformando-as em um plano nacional de comunicação ou em políticas públicas. A maioria ficou na gaveta e não saiu do papel"7

A grande mídia, que boicotou a Confecom ${ }^{8}$, seguiu associando as ações de movimentos pela democratização à ideia de censura e de ameaça à liberdade de expressão. Essa dinâmica se mantém até os dias atuais, mediante a cobertura das ações criminalizando os movimentos sociais. Outra postura adotada foi de silenciamento sobre o tema da democratização, que acabou excluído do debate público pela mídia.

Em paralelo, o governo - ator de relevância na implementação de políticas públicas - não enfrentou a temática da regulação dos meios, medida que acarretou, ainda mais, a redução dos espaços de interlocução da sociedade civil com o poder público. Em outras palavras, ainda que existam formas de regulação pública dos meios de

\footnotetext{
${ }^{6}$ Fórum Nacional pela Democratização da Comunicação.

7 Entrevista concedida ao autor.

${ }^{8}$ A Abert (Associação Brasileira de Rádio e Televisão), liderada pela TV Globo, foi uma das seis entidades do setor empresarial de comunicação que deixaram a conferência, sob a alegação de que os mecanismos de controle e participação social seriam contrários à liberdade de expressão.
} 
comunicação presentes em países democráticos, no Brasil esta discussão enfrenta barreiras para avançar. Nos dizeres de Sorj (2011, p. 9), “o que está em jogo, sobretudo, é garantir o direito de expressão, que inclui em primeiro lugar a liberdade de cada indivíduo e grupo de se expressar livremente no espaço público e o acesso universal à informação".

A agenda da democratização da comunicação ainda sofreu retrocessos no período recente. Em 2016, o governo interino de Michel Temer extinguiu o Conselho Curador da Empresa Brasil de Comunicação. O conselho era um dos principais espaços de participação social na comunicação pública. Considerando que o Brasil vinha construindo um sistema público de mídia, a eliminação do conselho indica a retirada do caráter público da Empresa Brasil de Comunicação e o desmonte da comunicação pública no país (CONSELHO, 2016).

Além de interferências políticas na comunicação pública e das dificuldades de prosseguimento das propostas da Confecom, aponta-se ainda alterações na distribuição de verba publicitária governamental, com a quebra de contratos firmados em governos anteriores junto a sites progressistas ${ }^{9}$, o que sinalizou uma estratégia de silenciar os veículos alternativos com ideias e proposições críticas ou divergentes em relação ao governo de turno.

Com as dificuldades para se debater o assunto, o Fórum Nacional pela Democratização da Comunicação lançou, em outubro de 2016, a campanha "Calar jamais!”. A iniciativa engloba ações de resistência à grande mídia e ao governo, pelo fato desses últimos dificultarem a garantia da liberdade de expressão e de manifestação ${ }^{10}$. Por meio de uma plataforma on-line, os cidadãos de todo o país são incentivados a denunciar ao fórum as transgressões à liberdade de expressão.

\footnotetext{
${ }^{9}$ Entrevista concedida ao autor por representantes do movimento social pela democratização da comunicação durante a $20^{a}$ Plenária do Fórum Nacional pela Democratização da Comunicação, realizada em Brasília, em 28 de maio de 2017. Para os segmentos que lutam pela democratização, na última década, a ampliação da destinação destas verbas vinha contribuindo para o fortalecimento de canais comunitários e alternativos. O movimento entende que as regras de destinação das verbas publicitárias do governo precisam mudar e serem descentralizadas, indo além do critério de audiência e alcance dos veículos, devendo considerar, por exemplo, se as diretrizes para a exploração do serviço de radiodifusão são seguidas.

${ }^{10}$ Os detalhes sobre a campanha como um todo e sobre as formas de recebimento das denúncias estão disponíveis no site: $<$ http://www.fndc.org.br/campanhas/calar-jamais/>.
} 
Essa estratégia revelou uma mudança no curso das reivindicações do movimento pela democratização da mídia, dado que a principal agenda do grupo fora alterada: se outrora a pauta prioritária era o marco regulatório da mídia, agora a tônica passou a ser a defesa da liberdade de expressão. Para o segmento da sociedade civil, não há como avançar na regulação e na consolidação da democracia se não houver comunicação democrática ${ }^{11}$.

Essa ideia de colocar a luta pela liberdade de expressão como centro de sua atuação política sinalizou uma alteração de postura nas ações do movimento social. Entretanto, para a coordenadora geral do Fórum, Renata Mielli, essa mudança não implica “abandono da pauta do marco regulatório, uma das razões de existência do próprio FNDC, mas sim que a organização está trabalhando com uma bandeira política mais direcionada à defesa da liberdade de expressão"12.

Como parte dessa nova temática enfatizada pela organização no pós-Confecom, o FNDC publicou um relatório em 2017 com o balanço de um ano de atuação da campanha, que recebeu mais de 70 denúncias sobre as violações à liberdade de expressão no Brasil. O documento compilou os casos recebidos de agressões e atos de censura contra jornalistas, comunicadores, servidores públicos e representantes de movimentos sociais.

Mesmo sem obter resultados práticos no que se refere à agenda da democratização das comunicações no período analisado, a sociedade civil organizada vem contribuindo para a veiculação de ações de resistência às informações veiculadas pela grande mídia. São informações contra-hegemônicas que conquistaram espaço na internet, nas redes sociais e nos sites. Se essas iniciativas fossem encampadas pelo Governo Federal, a participação cidadã teria mais voz na implementação de políticas no campo midiático.

A atuação de segmentos da sociedade, via canais de resistência e utilização das redes sociais e tecnológicas, pode ser definida como:

(...) a comunicação comunitária e alternativa, entendida como comunicação dos movimentos sociais, pensada em sentido geral - ou seja, como não restrita a movimentos populares específicos, mas englobando aquelas manifestações de organizações correlatas ou de outros atores coletivos atuantes no mesmo universo de preocupações e tendências políticas e ideológicas -, reposiciona-

\footnotetext{
${ }^{11}$ Entrevista concedida ao autor.

${ }^{12}$ Entrevista concedida ao autor.
} 
se na sociedade brasileira cumprindo importante papel na democratização da comunicação e da sociedade. (PERUZZO, 2011, p. 162)

Depreende-se desta análise que a falta de atualização do marco legal impede a ampliação de pluralidade de vozes, aspecto que tem sido trabalhado pela sociedade civil, por meio de ações de resistência às veiculações hegemônicas. A própria discussão sobre o tipo de mídia que se almeja no país e as proposições que concedem espaço a outros atores nas políticas orientadoras do setor já têm sido um avanço, do ponto de vista democrático, ainda que, na prática, a regulação dos meios esteja num horizonte distante.

\section{CONSIDERAÇÕES FINAIS}

A regulação das comunicações no Brasil ainda é um desafio. O histórico poder dos grandes meios de comunicação, beneficiado pela ausência de uma legislação abrangente, favorece a permanência de um quadro de legislação intocado por mudanças.

Possibilidades de alteração dessa situação surgiram com a $1{ }^{\mathrm{a}}$ Confecom, realizada há oito anos, mas não foram revertidas em políticas públicas nos últimos anos. Além do boicote dos grandes meios de comunicação, o governo não tomou providências no sentido dar prosseguimento às propostas.

O debate público sobre o tema acabou restrito à atuação da sociedade civil organizada que, apesar das ideias levantadas e do movimento promovido, não conseguiu resultados práticos. Um dos reflexos é verificado na principal pauta da conferência - o marco regulatório - que perdeu espaço em anos recentes.

A luta por maior espaço nas políticas de mídia levou a uma mudança de estratégia do movimento social em governos recentes. O tema da liberdade de expressão ganhou visibilidade e tem ocupado um espaço cada vez maior na internet, em sites e redes sociais.

Cumpre destacar que, embora com reduzidos ganhos em termos de políticas de mídia, essas ações contra-hegemônicas vêm por trazer inovações, na medida em que favorecem a democracia, ao defender a liberdade de expressão, a cidadania e a participação democrática.

\section{Referências}

CONSELHO de Comunicação critica fim de conselho curador da EBC. Agência Senado, 2016. Disponível em: $\quad<$ https://www12.senado.leg.br/noticias/materias/2016/10/10/conselho-decomunicacao-critica-fim-de-conselho-curador-da-ebc>. Acesso em: 13 jan. 2018. 
DANTAS, Marcos. Comunicações, desenvolvimento, democracia: desafios brasileiros no cenário da mundialização mediática. São Paulo: Perseu Abramo, 2013.

HOWLETT, Michel; RAMESH, M.; PERL, Anthony. Política pública, seus ciclos e subsistemas: uma abordagem integradora. Rio de Janeiro: Elsevier, 2013.

LIMA, Venício. Regulação das comunicações: história, poder e direitos. São Paulo: Paulus, 2011.

MEDIA Ownership Monitor Brasil. Mídia. Brasil, 2017. Disponível em: <https://brazil.momrsf.org/br/midia/>. Acesso em: 11 abr. 2018.

MENDEL, Toby; SALOMON, Eve. O ambiente regulatório para a radiodifusão: uma pesquisa de melhores práticas para os atores-chave brasileiros. Unesco, n.7, fevereiro de 2011. Disponível em: http://unesdoc.unesco.org/images/0019/001916/191622por.pdf. Acesso em: 12 fev. 2018. (Série Debates Comunicação e Informação).

PERUZZO, Cicilia. Movimentos sociais, cidadania e o direito à comunicação comunitária nas políticas públicas. In: MARQUES, Ângela; MATOS, Heloiza (Orgs.). Comunicação e política: capital social, reconhecimento e deliberação pública. São Paulo: Summus, 2011. p. 149-165.

PUDDEPHATT, Andrew. A importância da autorregulação da mídia para a defesa da liberdade de expressão. Unesco, n. 9, fevereiro de 2011. Disponível em: http://unesdoc.unesco.org/images/0019/001916/191624por.pdf. Acesso em: 11 jan. 2018.

SORJ, Bernardo. (Des)construindo a sociedade civil na América Latina. In: Usos, abusos e desafios da sociedade civil na América Latina. São Paulo: Paz e Terra, 2010. p.7-15.

. Meios de comunicação e democracia: para além do confronto entre governos e empresas. In: SORJ, Bernardo (Org.). Meios de comunicação e democracia: além do Estado e do mercado. Rio de Janeiro: Centro Edelstein de Pesquisas Sociais, 2011. p. 7-27.

UNESCO. Tendências mundiais sobre liberdade de expressão e o desenvolvimento da mídia. Brasília: $\quad$ Unesco, 2016. Disponível em: http://unesdoc.unesco.org/images/0024/002447/244708por.pdf. Acesso em: 31 jan. 2018.

YIN, Robert. Estudo de caso: planejamento e métodos. 4. ed. Porto Alegre: Bookman, 2010. 